\title{
TEOLOGI PUBLIK STANLEY HAUERWAS DAN PENERAPANNYA DALAM KONTEKS DI INDONESIA
}

\author{
Calvin Bangun \\ Sekolah Kristen Calvin, Jakarta
}

\begin{abstract}
ABSTRAK: Orang Kristen tidak dapat melarikan diri dari masyarakat sehingga teologi publik dibutuhkan oleh orang Kristen untuk berkontribusi kepada masyarakat. Pada satu aspek, teologi publik harus relevan dengan masyarakat tetapi di aspek yang lain harus dapat menunjukkan identitasnya. Terdapat banyak jenis teologi publik dan salah satunya diusulkan oleh Stanley Hauerwas. Hauerwas mengajukan sebuah model teologi publik yang berdasarkan komunitas dan narasi sehingga kontribusi orang Kristen tidak kehilangan identitasnya demi mendapatkan relevansi publik. Teologi publik Hauerwas menekankan peran gereja dalam teologi pubik. Sekalipun model ini didasarkan pada konteks Amerika Serikat tetapi dapat memberikan masukan yang bermanfaat dalam berteologi publik di Indonesia.
\end{abstract}

KATA KUNCI: narasi, komunitas, karakter, teologi publik, masyarakat, Stanley Hauerwas. 
ABSTRACT: Christian cannot escape from society therefore public theology is needed by the Christian in order to contribute to the society. In one aspect, public theology has to be relevant to the society but at the other side, it also must show its' identity. There are many variance of public theology, one of them is proposed by Stanley Hauerwas. Hauerwas proposes a model of public theology based on community and narrative hence Christian's contribution won't lose its' identity in pursuing public relevance. Hauerwas's public theology emphasizes the role of the church in public theology. Although this model based on United States context but it can offer beneficial insight for public theologizing in Indonesia.

KEYWORDS: narrative, community, character, public theology, society, Stanley Hauerwas.

\section{Pendahuluan}

Demi menggenapkan panggilannya di ruang publik gereja harus memiliki teologi publik. ${ }^{1}$ Kontribusi di ruang publik adalah bagian dari misi

1 Gagasan teologi publik pertama kali dikemukakan oleh Martin Marty, pada waktu itu dia menggunakan istilah gereja publik. Ronald F. Thiemann mendefinisikan teologi publik sebagai iman yang berusaha memahami kaitan antara kepercayaan Kristen dengan konteks budaya dan sosial yang lebih luas dimana komunitas Kristen itu berada. Robert Benne, The Paradoxical Vision: a Public Theology for the Twenty-First Century (Minneapolis: Augsburg Fortress Publishers, 1995), 3-4.

Konsep teologi publik seringkali dianggap identik dengan agama sipil padahal keduanya berbeda. Mary Doak memberikan 3 perbedaan antara keduanya, yaitu:

1) agama sipil bertujuan untuk memakai simbol dan kepercayaan agama untuk mendukung nilai dan tindakan sebuah negara sedangkan teologi publik tidak hanya bertujuan untuk memberi dukungan tetapi juga refleksi kritis terhadap budaya, rencana, dan aksi sebuah negara.

2) agama sipil menggunakan simbol, kepercayaan, dan ritual agama yang diterima oleh 
gereja sebab "no sphere of human life is concieveable in which religion does not maintain its demands that God shall be praised, that God's ordinances shall be observed..."2 Eka Darmaputera, seorang teolog Indonesia, mengatakan gereja harus melakukan transformasi budaya di sekitarnya karena budaya adalah "area of human life which comes under the universal Lordship of Christ..."3

Tulisan ini akan memaparkan tentang teologi publik Stanley Hauerwas. ${ }^{4}$ Sekalipun Hauerwas belum dikenal luas dalam konteks pembaca di Indonesia tetapi dia adalah teolog-etis yang sangat berpengaruh di Amerika Utara bahkan di seluruh dunia. Dalam bagian pengantar The Hauerwas Reader, John Berkmann menyebutnya sebagai "the most prolific and

sebagian besar komunitas sedangkan teologi publik menggunakan setiap kelompok agama dapat menggunakan tradisinya untuk menjawab kebutuhan publik.

3) agama sipil memakai simbol dan kepercayaan agama di dalam publik tanpa kontekstualisasi sedangkan teologi publik berusaha untuk mengkontekstualisasikan tradisi dan praktek dari suatu kelompok agama yang dikembangkan melalui keterlibatan yang kritis dengan gagasan dan praktek di publik. Lih. Mary Doak, Reclaiming Narrative for Public Theology, (Albany: State University of New York Press, 2004), 5-6.

2 Kuyper, Lectures on Calvinism (Grand Rapids: Eerdmans, 1931), 53.

Abraham Kuyper terkenal dengan kalimatnya "There is not a square inch in the whole domain of our human life of which Christ, Who is Sovereign of all, does not cry: "Mine!, Abraham Kuyper, 'Sphere Sovereignty' dalam Abraham Kuyper: A Centennial Reader. diedit oleh Bratt, James D (Grand Rapids: Eerdmans, 1988), 488.

3 Eka Darmaputera, Pancasila and the Search for Identity and Modernity in Indonesian Society: a Cultural and Ethical Analysis (New York: Brill, 1997), 223.

4 Saat ini Hauerwas menduduki posisi sebagai Gilbert T. Rowe Professor Emeritus of Divinity and Law dan Senior Research Fellow at the Duke University Divinity School dan sejak 2014, menjadi profesor paruh waktu dalam Theological Ethics di University of Aberdeen. Dia pernah diundang untuk memberikan sebuah ceramah yang bergengsi yaitu Gifford Lectures di University of St. Andrews, Skotlandia. Berbagai universitas bergengsi telah menganugerahkan gelar kehormatan kepadanya seperti DePaul University, the University of Edinburgh, Virginia Theological Seminary dan the University of Geneva. Dia telah menulis dan mengedit lebih dari tiga puluh buku dan mempublikasikan lebih dari tiga ratus lima puluh artikel ilmiah. Lih. dalam University of Aberdeen, "World-renowned theologian joins University of Aberdeen", diakses 27 September 2014, http://www.abdn.ac.uk/news/6458/ 
comprehensive theological ethicist alive."5 Majalah TIME menjulukinya sebagai teolog Amerika yang terbaik dan dalam majalah tersebut Jean Bethke Elsthain seorang teolog Lutheran yang dipilih oleh majalah Times sebagai penulis profil Hauerwas mengatakan "Hauerwas is contemporary theology's foremost intellectual pro- vocateur."6

\section{Tokoh-tokoh yang Mempengaruhi Hauerwas}

Pemikiran Hauerwas sebagian besar dibentuk oleh teolog-teologi yang dipelajarinya selama kuliah di Yale School of Divinity sejak 1963. Hauerwas sendiri mengatakan "I had a wonderful education at Yale, and I have spent a lifetime to think it through. I am not sure if I became a Christian at Yale but I certainly began to be a theologian because of what I learned there."7

Sekalipun Hauerwas tidak pernah bertemu langsung dengan Karl Barth tetapi dia mempelajari teologi Barth selama berada di Yale dan sangat dipengaruhi oleh Barth di kemudian hari. Tidak berlebihan jika Stephen Webb mejuluki Hauerwas sebagai "American's Barth."8 Todd Cioffi mengatakan antitesis antara gereja dan dunia yang dibangun oleh Hauerwas adalah penafsirannya terhadap pemikiran Barth dalam konteks demokrasi Amerika. Cioffi mengatakan:

5 John Berkman, "An Introduction to The Hauerwas Reader,"dalam The Hauerwas Reader, diedit oleh John Berkman dan Michael Cartwright (Durham dan London: Duke University Press, 2001), 3 .

6 Joel D Lehenbauer. "The theology of Stanley Hauerwas." Concordia Theological Quarterly 76, no. 1-2 (January 1, 2012): 157.

7 Stanley Hauerwas, Hannah's Child: A Theologian's Memoir, (Grand Rapids: Eerdmans, 2012), 49.

8 Stephen H. Webb, "The very American Stanley Hauerwas," First Things no. 124 (2002): 15. 
The plot of Hauerwas' story is driven by Barth, and we were led to believe that Barth, too, is trying to tell a story about the church being a counter-politics to the world, and in Hauerwas terms...this means an antipathy toward secularism, political liberalism, especially American Democracy. ${ }^{9}$

Pandangan Hauerwas tentang narasi dipengaruhi oleh dua teolog Yale yaitu Hans Frei dan George Lindbeck. Keduanya adalah teolog dari Universitas Yale yang sangat berpengaruh dalam dunia teologi naratif. Herman Paul mengatakan pemikiran kedua teolog ini mempengaruhi Hauerwas dalam melihat bahwa iman Kristen pada dasarnya adalah sebuah kisah mengenai "God's covenant with Israel, about the life, death, and resurrection of Jesus, and about a church whose members, in turn, seek to conform their stories to God's story. ${ }^{10}$

Di kemudian hari, Hauerwas dipengaruhi oleh John Howard Yoder, seorang teolog Anabaptis. Yoder mengubah pandangan Hauerwas mengenai etika sosial. Peran gereja di dalam masyarakat bukanlah untuk mengubah masyarakat melainkan menjadi komunitas yang menyaksikan Kerajaan Allah. Yoder ingin gereja bersepon terhadap isu-isu publik dengan berintegritas yaitu dengan mengajukan nilai-nilai yang dihidupi dalam komunitas Kristen sekalipun kelihatan tidak relevan dan realistis untuk dihidupi di dunia. ${ }^{11}$ Pengaruh Yoder ini terlihat dalam sebuah slogan yang sering diulang-ulangi dalam karya Hauerwas "the church does not have a social

9 Todd V. Cioffi, 'Stanley Hauerwas and Karl Barth' dalam Karl Barth and American Evangelicalism diedit oleh Bruce L. McCormack dan Clifford B. Anderson (Grand Rapids: Eerdmans, 2011), 363.

10 Herman Paul,"Stanley Hauerwas: against secularization in the church," Zeitschrift Für Dialektische Theologie 29, no. 2 (2013): 15.

11 Gary Dorrien, Social Ethics in the Making: Interpreting an American Tradition (Chichester: Wiley-Blackwell, 2009), 477. 
ethic; the church is a social ethic." 12

\section{Pemikiran Hauerwas dalam Teologi Publik}

Sebagaimana yang telah digambarkan sebelumnya bahwa Hauerwas adalah seorang teolog naratif dan pendukung etika kebajikan sehingga pemikirannya dalam teologi publik tidak dapat dipisahkan dari dari konsep-konsep berikut ini: naratif, komunitas, karakter dan kebajikan.13 Supaya dapat memahami teologi publiknya maka perlu untuk membahas keempat konsep ini.

\section{Narasi dan Komunitas}

Hauerwas mengatakan"the very nature of ethics is determined by the particularities of a community's history and conviction."14 Dia menganggap peran komunitas sangat penting sebagai pengkualifikasi sebuah sistem etika. ${ }^{15}$ Dengan demikian etika apapun bersifat komunal dan tidak mungkin membuat sebuah etika yang berlaku universal.

Komunitas sangat berhubungan dengan narasi karena sebuah komunitas terbentuk melalui narasi yang dipegang oleh anggotaanggotanya. Hauerwas mengatakan sebuah narasi membutuhkan komunitas koresponden yang dapat mengingat dan menafsirkan ulang

12 Stanley Hauerwas, The Peaceable Kingdom: A Primer in Christian Ethics (Notre Dame: University of Notredame Press, 1983), 99.

13 Patrick Nullens dan Ronald T. Michener, The Matrix of Christian Ethics: Integrating Philosophy and Moral Theology in a Postmodern Context (Downers Grove: Intervarsity Press, 2010), 126.

14 Hauerwas, Peaceable Kingdom, 1.

15 Ibid., 2. 
narasi tersebut secara terus menerus sehingga terciptalah sebuah cari hidup komunitas yang khas. ${ }^{16}$

Komunitas dan narasi kemudian sangat berpengaruh terhadap kebajikan. ${ }^{17}$ Itulah sebabnya etika kebajikan tidak dapat dilepaskan dari komunitas dan narasi karena dalam setiap masyarakat atau komunitas terdapat narasi yang menggambarkan seperti apakah seharusnya seorang yang berkarakter dan kebajikan apakah yang penting dalam kehidupan moral komunitas tersebut. ${ }^{18}$

Kaitan antara etika, narasi dan komunitas juga berlaku dalam etika Kristen. Etika Kristen memerlukan komunitas Kristen sebagai pengkualifikasinya. Hauerwas mengatakan kepercayaan Kristen berbentuk seperangkat cerita yang membentuk tradisi dan kemudian membentuk komunitas. ${ }^{19}$ Dengan demikian keberadaan gereja sangat penting dalam pembentukan etika Kristen karena di dalam gerejalah orang Kristen diuji berdasarkan narasi yang dihidupinya. ${ }^{20}$

Gagasan Hauerwas mengenai komunitas ini sangat memengaruhi teologi publiknya. Hauerwas mengatakan "all politics should be judged by the character of the people it produces. The depth and variety of character which a polity sustains is a correlative of thenarrative that provides its identity and purpose..$^{21}$

16 Stanley Hauerwas, A Community of Character: Toward a Constructive Christian Social Ethic (Notre Dame: University of Notre Dame Press, 1981), 54.

17 Ibid., 115-116.

18 Ibid., 121.

19 Hauerwas, Peaceable Kingdom, 25.

20 Hauerwas, Community of Character, 96.

21 Ibid., 52. 
Dengan demikian gereja seharusnya sebagai komunitas menunjukkan dirinya sebagai sebuah polis dengan narasi yang berbeda. Sebagai komunitas yang menghidupi narasi yang berbeda, gereja seharusnya menampakkan sumbangan yang berbeda di dalam publik. Sebab itu Hauerwas mengatakan "The social ethical task of the church, therefore, is to be the kind of community that tells and tells rightly the story of Jesus." 22 Gereja harus memperlihatkan keunikan narasinya dalam berkontribusi dalam publik yang tidak terdapat dalam komunitas lain bahkan negara. Dalam hal ini Hauerwas menambahkan "[T]he contention and witness of the church is that the story of Jesus provides a flourishing of gifts which other politics cannot know."23

\section{Karakter dan Kebajikan}

Hauerwas menggunakan model etika kebajikan dalam teologi publiknya. Etika kebajikan lebih berorientasi kepada subyek daripada keputusan yang diambilnya tersebut. ${ }^{24}$ Etika kebajikan berupaya untuk menjawab kegagalan etika modern yang berfokus pada pengambil keputusan seperti etika deontologis dan utilitarian. Kegagalan etika modern disebabkan oleh dua alasan, yaitu: pertama, kebanyakan tindakan yang diambil seseorang dalam hidupnya bukanlah karena pilihan melainkan karena identitasnya. Kedua, ketika terjadi krisis yang membutuhkan keputusan yang besar maka keputusan tersebut tidak diambil dalam ruang

\footnotetext{
22 Ibid.

23 Ibid., 51-52

24 Hauerwas, A Community of Character, 113.
} 
vakum melainkan bergantung pada komitmen moral yang lebih dalam. ${ }^{25}$ Etika modern tidak dapat memberitahukan bagaimana menggunakan aturan-aturan atau prinsip-prinsip dalam situasi tertentu atau kapan situasi yang terbaik untuk menggunakannya. ${ }^{26}$

Dalam konteks inilah Hauerwas melihat pentingnya kebajikan dan karakter dalam etika, khususnya etika Kristen. Hauerwas menganggap pusat refleksi moral bukanlah perkembangan solusi atau prinsip dalam membuat sebuah keputusan moral melainkan perkembangan karakter seseorang. ${ }^{27}$ Hauerwas bukan meniadakan pentingnya keputusan atau tindakan dalam etika tetapi menempatkan kebajikan dan karakter seseorang lebih utama daripada keputusan dan tindakan moralnya. ${ }^{28}$ Tetapi bukan berarti etika kebajikan adalah etika individualis yang menekankan pada moralitas pribadi karena menurut Hauerwas dalam etika kebajikan tidak terdapat perbedaan antara moralitas publik dan privat ataupun sosial dan individual. ${ }^{29}$

Menurut pandangan Hauerwas sebuah tindakan atau keputusan moral harus selaras dengan kebajikan yang tertanam dalam kepribadian subyek yang memutuskan. ${ }^{30}$ Seorang subyek yang bertindak harus dapat

\footnotetext{
25 Samuel Wells, Transforming Fate Into Destiny: The Theological Ethics of Stanley Hauerwas (Eugene: Cascade, 1998), 13.

26 Ibid., 18.

27 Wells, Transforming Fate Into Destiny, 16-17.

28 Hauerwas mengatakan "from the perspective of virtue, in a certain sense decisions are morally secondary...the virtuous person makes decisions, but they are viewed as dependent on a more profound moral reality.", A Community of Character, 114.

29 Ibid., 121.

30 Ibid., 114.
} 
mengklaim tindakan tersebut sebagai miliknya. ${ }^{31}$ Seorang pribadi yang berintegritaslah yang ingin dicapai oleh etika kebajikan sebagaimana yang dikatakan Hauerwas. ${ }^{32}$

Kebajikan sangat penting bagi anggota komunitas. Tanpa kebajikan seorang anggota komunitas tidak dapat menghidupi narasi ataupun tradisi komunitasnya dengan tekun. Untuk mendapatkan kebajikan dibutuhkan latihan karena kebajikan lebih merupakan sebuah keahlian daripada teknik. Kebajikan adalah sebuah keahlian yang melibatkan linguistik, emosi, dan rasio. Seorang yang sudah terbentukkebajikan dalam dirinya akan mampu mengambil keputusan secara kreatif saat menghadapi kesulitan yang tidak diantisipasi sebelumnya. ${ }^{33}$

Etika kebajikan menempatkan subyek yang memutuskan dalam posisi yang bebas untuk memutuskan bukan sekedar harus membuat pilihan walaupun yang tidak diinginkannya. Menurut Hauerwas orang yang berkarakter memiliki kendali atas dirinya dan keputusan-keputusannya. ${ }^{34}$ Orang yang berkebajikan tetap menghadapi pilihan-pilihan yang sulit dalam hidupnya tetapi Hauerwas mengatakan "if we are virtuous, we can deal with the onerous on our terms." 35 Dalam kondisi seperti ini seorang yang berkebajikan dapat memutuskan dengan bebas. Orang yang berkebajikan dapat mengambil keputusan yang tidak dapat diambil oleh orang yang

\footnotetext{
31 Ibid., 115.

32 Ibid., 116.

33 Ibid., 115.

34 Stanley Hauerwas, Character and the Christian Life: A Study in Theological Ethics (Notre Dame: University of Notre Dame Press, 1994), 13.

35 Hauerwas, Community of Character, 115.
} 
tidak berkebajikan dalam kondisi yang sulit. ${ }^{36}$

\section{Confessing Church}

Hauerwas melihat gereja-gereja di Amerika Serikat baik injili maupun liberal gagal dalam menunjukkan antithesis antara gereja dan dunia dalam teologi publiknya. Kedua tipe tersebut "assumed a basically Constantinian approach to the issue of church and world" 37 karena "[b]oth assume wrongly that the American church's primary social task is to underwrite American democracy." 38 Hauerwas melihat gereja-gereja di Amerika Serikat masih mengganggap struktur politik dapat diakomodasi untuk melakukan transformasi dalam masyarakat.

Hauerwas memang hidup dalam konteks teologi publik yang mengarah pada transformasionis. Para teolog publik transformasionis yang hidup sebelum Hauerwas seperti Reinhold Niebuhr, H. Richard Niebuhr, dan Walter Rauschenbusch, memang meyakini bahwa kekristenan dapat

\footnotetext{
36 Ibid.

37 Istilah Konstantinian diambil dari nama seorang kaisar Romawi yaitu Konstantinus. Pada masa pemerintahannya, agam Kristen menjadi agama resmi negara. Konstantinian menggambarkan sebuah persekutuan formal antara negara dengan gereja. Gereja dapat menggunakan kekuasaan negara untuk mencapai tujuannya dan sebaliknya negara membutuhkan gereja untuk mempersatukan masyarakatnya. Pada zaman Konstantin, kekristenan dijadikan sebagai kekuatan sosial untuk mempersatukan seluruh kekaisaran Romawi. Hauerwas mengatakan "in order to keep the Empire afloat, if people were no longer classically pagan, they would have to be made imperially Christian. You cannot run a world without people believing in something." Ini merupakan kesempatan yang besar bagi kekristenan untuk mendapatkan posisi penting secara sosial dan politik dalam kekaisaran sehingga "Christians somehow have a stake in transforming our ecclesial claims into intellectual assumptions that will enable us to be faithful to Christ while still participating in the political structures of a world that does not yet know Christ." Lih. Hauerwas dan Willimon, Resident Aliens, 22.
}

38 Ibid., 31-32. 
dan harus mengambil bagian dalam membuat dunia menjadi tempat yang lebih baik. Hauerwas tidak menyetujui tipologi Christ transformed culture yang diusulkan oleh Richard Niebuhr. ${ }^{39}$ Hauerwas mengingatkan "the political task of Christians is to be the church rather than to transform the world." 40 Hauerwas melihat teologi publik transformasionis Niebuhrian memiliki bahaya yaitu "merely justified what was already there-a church that had ceased to ask the right questions as it went about congratulating itself for transforming the world, not noticing, that in fact the world had tamed the church" 41 Menurut Hauerwas dalam teologi publik seperti ini sukses menjadikan peran sosial gereja diterima dalam masyarakat tetapi tidak memberikan kepekaan membedakan baik dan jahat dalam struktur budaya yang ditransformasinya. ${ }^{42}$

Orang Kristen harus dapat membedakan antara yang baik dan jahat di dalam struktur masyarakat. Sebab itu tanggung jawab utama gereja dalam masyarakat dan negara adalah menunjukkan kepada dunia diri mereka yang sebenarnya ${ }^{43}$ dan hal ini hanya dapat terjadi jika orang Kristen hidup sebagai gereja ${ }^{44}$ sebab gereja yang memberikan "the interpretive skills, a truthful understanding whereby we first see the world for what it is." 45

\footnotetext{
39 H Richard Niebuhr, Christ and Culture (New York: Harper \& Brothers, 1956)

40 Hauerwas dan Willimon, Resident Aliens, 38.

41 Ibid., 41.

42 Ibid., 40.

43 Stanley Hauerwas, "The Servant Community," dalam The Hauerwas Reader diedit oleh John Berkman dan Michael Cartwright (Durham dan London: Duke University Press, 2001), 377.

44 Ibid., 38

45 Ibid.
} 
Hauerwas menolak model teologi publik yang diusulkannya sebagai sektarian. Dia mengatakan" [t]his does not involve a rejection of the world, or a withdrawal from the world; rather it is a reminder that the church must serve the world on her own terms." 46 Hauerwas menegaskan "[t]he gospel is political. Christians are engaged in politics, a politics of the kingdom" 47 dan "Christianity is mostly a matter of politics - politics as defined by the gospel." 48

Tetapi Hauerwas melihat dalam gereja di Amerika Serikat terdapat dua kecenderungan, yang disebutnya sebagai activist church dan conversionist church. Pada satu sisi, gereja aktivis menunjukkan "Christian enthusiasm for the political involvement offered by our secular polity has made us forget the church's more profound political task" tetapi di sisi lain gereja konversionis yang menunjukkan "attempts by Christians to avoid political involvement because of the [dirty] nature of politics are rightly condemned asirresponsible, if not unfaithful." Hauerwas mengatakan gereja aktivis sebagai" a sort of religiously glorified liberalism" karena lebih mengutamakan "the building of a better society than with the reformation of the church." 49 Sedang di sisi yang lain, Hauerwas menyebut gereja konversionissebagai "religiously glorified conservatism" karena beranggapan bahwa "tinkering with the structures of society will counter the effects of human sin." 50

Hauerwas ingin gereja tidak mengikuti cara berpolitik di dunia karena tanggung jawab utama gereja adalah memberikan kepada orang

\footnotetext{
46 Hauerwas, A Community of Character, 85.

47 Ibid.

48 Hauerwas dan Willimon, Resident Aliens, 30.

49 Ibid., 45.

50 Ibid.
} 
Kristen kemampuan untuk menafsirkan dan membedakan sehingga dapat mengenali keterbatasan masyarakat yang hanya dapat diperoleh jika keterlibatan politis orang Kristen dilakukan di dalam gereja. Sebab itu Hauerwas mengusulkan tipe gereja ketiga sebagai alternatif radikal terhadap dua tipe sebelumnya yang disebutnya sebagai confessing church. Menurut Hauerwas "confessing church finds its main political task to lie, not in the personal transformation of individual hearts or the modification of society, but rather in the congregation's determination to worship Christ in all things."51

\section{Kelebihan Teologi Publik Hauerwas}

Teologi publik yang diusulkan oleh Hauerwas memiliki perbedaan dengan teologi publik Calvinis sebagaimana yang dikatakan Nullens dan Michener "Hauerwas' work represents an invigorating and contrasting alternative to the Calvinist command ethic."52 Sekalipun demikian ada kelebihankelebihan yang bisa diapresiasi dan dipelajari dari teologi publiknya.

\section{Signifikansi Gereja dalam Teologi Publik}

Hauerwas mengatakan "my primary interest is to challenge the church to regain a sense of the significance of the polity that derives from convictions peculiar to Christians"53 Kelebihan yang dapat diapresiasi dari teologi publik Hauerwas adalah pentingnya gereja. Hauerwas berulang kali mengatakan bahwa gereja tidak memiliki etika sosial karena gereja adalah etika sosial.

\footnotetext{
51 Hauerwas dan Willimon, Resident Aliens, 45.

52 Nullens dan Michener, The Matrix of Christian Ethics, 126.

53 Hauerwas, A Community of Character, 1-2.
} 
Hauerwas menginginkan aktivitas politik yang dilakukan oleh orang Kristen adalah aktivitas politik yang dilakukan dalam gereja. Hauerwas menolak menjadikan gereja sekedar mengurusi hal-hal rohani.

Kebanyakan kaum Injili menganggap gereja sebagai komunitas rohani sehingga tidak perlu mengurusi isu-isu sosial dan politik. Kalaupun kekristenan mempengaruhi negara atau pemerintahan maka sarananya bukan gereja sebagai institusi tetapi melalui anggota-anggotanya. Hauerwas mengatakan bahwa gereja adalah sebuah komunitas politik alternatif. Sebagaimana kehidupan politik berlangsung di dalam sebuah polis atau komunitas demikian juga gereja dapat memperlihatkan kehidupan politik yang berbeda dalam sebuah polis yang berbeda "by taking seriously its task to be an alternative polity, the church might well help us to experience what a politics of trust can be like." 54 Di tempat yang lain Hauerwas mengatakan:

Thus it is not without reason that Christians claim that the polity of the church is the truest possible for human community. It is from the life of the church, past, present, and future, that we even come to understand the nature of politics and have a norm by which all other politics can be judged.That the church has often failed to be such a polity is without question, but the fact that we have often been less than we were meant to be should never be used as an excuse for shirking the task of being the people of God. ${ }^{55}$

Hauerwas mengingatkan orang Kristen supaya dalam berteologi publik gereja tidak terjebak dalam agenda pemerintah sebab:

[T] he church's first task is not to make the nation-state system work, but rather to remindus that the nation, especially as we know it today, is not an ontological necessity for humanliving. The church, as an international society, is a sign that God,

\footnotetext{
54 Ibid., 86.

55 Ibid., 2.
} 
not nations, rule this world. ${ }^{56}$

\section{Kekristenan sebagai Kontra-Budaya}

Hauerwas berulang kali mengingatkan bahaya Konstantinian yang mengintip di belakang teologi publik yang dihidupi oleh gereja di Amerika. Ketika gereja menginginkan posisi dalam pemerintah atau negara dengan maksud untuk melakukan perubahan maka gereja akan kehilangan kemampuannya untuk menunjukkan kesalahan dunia di sekitarnya.

Teologi publik Hauerwas perlu dijadikan alarm peringatan oleh gereja-gereja baik Liberal ataupun Injili. Selama ini gereja Liberal diidentikan dengan perannya di publik tetapi belakangan ini gereja Injili pun mulai menunjukkan perannya di publik. Hunter mengatakan sejak 1970-an, gereja Injili sudah muncul di publik dengan agenda sosialnya. ${ }^{57}$ Hauerwas ingin menjadikan Kekristenan sebagai budaya tandingan di masyarakat dimana dia berada. Hauerwas menginginkan sebuah teologi publik yang benar-benar menunjukkan identitas Kristen yang berbeda dengan gagasan-gagasan lain yang ada di masyarakat. Budaya tanding Kristen hanya dapat diwujudkan dalam sebuah komunitas Kristen. Hauerwas mengatakan asumsi Konstantinian mengatakan bahwa Injil tidak dapat hadir dalam dunia tanpa dukungan struktur institusi sosial dan politik dunia sehingga etika Kristen harus disesuaikan dengan komunitas yang bukan Kristen. Hauerwas mengingatkan etika Kristen yang terlepas dari komunitas Kristen akan mengubah Injil menjadi agama sipil.58

\footnotetext{
56 Ibid., 109-110.

57 Hauerwas dan Willimon, Resident Aliens, 31.

58 Ibid., 81.
} 
Kekristenan dapat menghadirkan budaya tanding dalam dunia ketika orang-orang Kristen menghidupi nilai-nilai yang dipegang oleh komunitasnya.

Sekalipun gereja tidak selalu harus berkontradiksi dengan dunia sebagai ciptaan Allah tapi gereja harus mengingat bahwa dunia sebagai ciptaan Allah pun sudah berdosa sehingga tidak semuanya bisa diadopsi oleh orang percaya. Dalam situasi seperti ini gereja perlu menghadirkan sebuah kontra budaya terhadap kebijakan-kebijakan yang dihasilkan dalam dunia.

\section{Kritik terhadap Teologi Publik Hauerwas}

Ditinjau dari sudut pandang teologi Reformed, teologi publik Hauerwas memiliki beberapa kekurangan, yaitu: Anugerah Umum dan Lapisan Kedaulatan (Sphere Sovereignty).

Teologi Reformed mengakui adanya anugerah umum yaitu anugerah yang diberikan Allah kepada semua manusia. Anugerah ini memungkinkan orang-orang tidak percaya menghasilkan perbuatan atau karya yang indah. Kuyper menggambarkan anugerah umum sebagai berikut:

Anugerah ini tidak mematikan inti dosa, juga tidak menyelamatkan ke dalam hidup yang kekal, tetapi menahan agar dosa jangan sampai berkembang, seperti halnya pengertian manusia dapat menahan kemarahan binatang buas. Manusia dapat mencegah binatang buas melakukan hal yang merusak; pertama, dengan mengerangkengnya; kedua, dengan menundukkan binatang kepada kehendaknya dengan menjinakkannya; ketiga, dengan membuatnya menarik dengan mendomestikasikannya...Dengan cara yang sama, melalui "anugerah umum"Nya Allah mengendalikan beroperasinya dosa di dalam manusia, sebagian dengan menghancurkan kuasanya, sebagian dengan 
menjinakkan rohnya yang jahat, dan sebagian dengan mendomestikasikan bangsa atau keluarganya. ${ }^{59}$

Keberadaan anugerah umum di dunia membuat orang percaya dapat bersikap positif terhadap ciptaan. Berbeda halnya dengan Hauerwas yang ingin menempatkan komunitas orang percaya berkontradiksi dengan ciptaan dan mengajak orang percaya untuk membentuk komunitas tandingan terhadap dunia. Berkaitan dengan hal ini Kuyper mengatakan “Namun dengan pengakuan ini menempatkan orang Kristen pada posisi yang agak berlainan terhadap hidup, sebab dalam penilaiannya, bukan hanya Gereja, tetapi juga dunia, adalah milik Allah..."60

Teologi Publik Hauerwas yang berorientasi kepada gereja melupakan bahwa Allah menciptakan berbagai institusi dengan kedaulatan yang berbeda. Institusi gereja memiliki kedaulatan atau tanggung jawab yang berbeda dengan institusi yang lain sepertinegara, sekolah, perusahaan, dankeluarga. Kuyper menegaskan di dalam dunia ciptaan Allah terdapat lapisan kedaulatan (sphere of sovereignty). Kedaulatan mutlak hanya milik Allah tetapi Allah mendelegasikan kedaulatan tersebut kepada institusi yang berbeda dan setiap institusi bekerja sesuai dengan kedaulatan yang dimilikinya yang disebutnya sebagai Kuyper mengatakan:

\footnotetext{
59 Abraham Kuyper, Ceramah-ceramah Mengenai Calvinisme (Surabaya: Momentum, 2005), 145.

60 Ibid., 146.
} 
Kedaulatan Allah, yang turun ke atas manusia, memisahkan dirinya menjadi dua wilayah. Di satu sisi, wilayah mekanis melalui otoritas negara, dan di sisi lain, wilayah organis melalui otoritas lingkaran-lingkaran sosial. Dan dalam kedua wilayah, otoritas inheren yang ada itu berdaulat, artinya, tidak ada yang lain di atas dirinya selain Allah. ${ }^{61}$

Dengan adanya lapisan kedaulatan, maka negara memiliki kedaulatan dalam bidang politik. Orang Kristen yang ingin terjun ke dalam bidang politik memang harus memakai sarana negara. Kuyper mengatakan:

Pemerintah memiliki hak dan kewajiban rangkap tiga yaitu:

1. Kapan saja terjadi bentrokan yang berbeda, pemerintah berkewajiban untuk memaksa terjadinya sikap saling menghargai garis-garis batas masingmasing.

2. Untuk membela individu-individu dan orang-orang yang lemah, dalam wilayah itu dari pelecehan oleh orang-orang lainnya; dan

3. Untuk memaksa semua lingkungan untuk bersama-sama menanggung beban-beban pribadi dan finansial untuk pemeliharaan kesatuan natural negara. ${ }^{62}$

Tugas-tugas yang disebutkan oleh Kuyper di atas berhubungan dengan kesejahteraan masyarakat di dalam sebuah negara. Orang Kristen yang terpanggil memperjuangkan ketiganya harus masuk dalam politik yang ada dalam negara dan pemerintahan.

\section{Relevansi di Publik}

Hauerwas begitu menekankan pada komunitas dan narasi sehingga teologi publiknya hanya relevan dilakukan dalam komunitas Kristen. Hauerwas tidak setuju jika etika Kristen diabstraksi dan dicari prinsip-

\footnotetext{
61 Ibid., 107.

62 Ibid., 110.
} 
prinsip umumnya untuk diterapkan dalam dunia. Bagi Hauerwas pemahaman dunia dengan kekristenan tidak memiliki persamaan walaupun menggunakan istilah yang sama. Hauerwas mengatakan sebagai berikut:

Big words like "peace" and "justice," slogans the church adopts under the presumption that, even if people do not know what "Jesus Christ is Lord" means, they will know what peace and justice means, are words awaiting content. The church really does not know what these words mean apart from the life and death of Jesus of Nazareth. After all, Pilate permitted the killing of Jesus in order to secure both peace and justice (Roman style) in Judea. It is Jesus' story that gives content to our faith, judges any institutional embodiment of our faith, and teaches us to be suspicious of any political slogan that does not need God to make itself credible. ${ }^{63}$

Sebab itu teologi publik Hauerwas memiliki nuansa sektarian. James Gustafson mengatakan sebagai berikut:

In Hauerwas's case, for example, this means that Christian morality is not based on a concern to be responsible participants in the ambiguities of public choices. It is rather based on its fidelity of the biblical narratives, and particularly to the gospel narratives. Thus the principal criterion for judging Christian behavior is its conformity to the stories of Jesus. For Hauerwas this means, for example, that Christian morality must be pacifist because he reads the gospel narratives as pacifist. In this example, we have wedded a way of doing theology-narratives--to an ecclesiology-classically sectarian-and to an ethic which is also classically sectarian. ${ }^{64}$

\section{Teologi Publik Hauerwas dan Gereja di Indonesia}

Kritik terhadap Teologi Publik Berbasiskan Nasionalisme

Konteks berteologi publik Hauerwas berbeda dengan konteks di Indonesia. Teologi publik Indonesia dipengaruhi oleh konteks masyarakat majemuk dan kekristenan merupakan salah satu agama minoritas dan

63 Hauerwas dan Willimon, Resident Aliens, 38.

64 James Gustafson, "The Sectarian Temptation: Reflections on Theology, the Church and the University," Proceedings of the Catholic Theological Society 40 (1985): 88. 
memiliki label sebagai agama warisan kolonial Belanda. Kondisi tersebut menyebabkan teologi publik harus menghindari kesan sektarian yang hanya mencerminkan kepentingan satu kelompok melainkan harus bersifat inklusif yang dapat merangkul kepentingan bersama. Dalam mencapai tujuan ini maka lahirlah teologi publik yang berbasiskan nasionalisme.

Teologi publik yang berbasiskan nasionalisme sudah berkembang sejak masa perang kemerdekaan karena gereja sedang bergumul dengan identitas ke-Indonesiaan-nya sehingga tidak mengherankan orang Kristen menggunakan bahasa nasionalisme untuk menyalurkan gagasan-gagasan Kekristenannya di dalam masyarakat. ${ }^{65}$ Julianus Mojau mengatakan bahwa teologi publik berbasiskan nasionalisme ini sebagai teologi sosial modernisme yang memiliki keyakinan bahwa politik modernisasi yang dijalankan Orde Baru dalam bentuk pembangunan nasional sebagai pengamalan Pancasila adalah satu-satunya pilihan untuk mengatasi masalah-masalah sosial di Indonesia. ${ }^{66}$ Dengan model teologi publik seperti ini gereja dapat menghindari stereotip sosial yang sangat kental di sebagian kalangan Islam yang memandang gereja sebagai bagian dari kolonialisme Belanda. ${ }^{67}$

Teologi publik berbasiskan nasionalisme telah menjadi motif teologi publik Indonesia sejak perang kemerdekaan sampai Orde Baru dan kelihatannya berhasil membuat kontribusi kekristenan diterima dalam

\footnotetext{
65 Emmanuel Gerrit Singgih, Mengantisipasi Masa Depan: Berteologi Dalam Konteks di Awal Milenium III, (Jakarta: BPK Gunung Mulia, 2004), 113.

66 Julianus Mojau, Meniadakan Atau Merangkul? Pergulatan Teologis Protestan Dengan Islam Politik di Indonesia, cetakan ke-1 (Jakarta: BPK Gunung Mulia, 2012), 139-40.

67 Mojau, Meniadakan atau Merangkul, 139.
} 
masyarakat majemuk. Tetapi motif ini secara sadar atau tidak sadar telah menyebabkan gereja mengakomodasi struktur yang ada. Dalam hal inilah gereja di Indonesia perlu mendengarkan teologi publik Hauerwas, khususnya tentang antitesis gereja dan negara. Hauerwas tidak ingin gereja jatuh ke dalam proyek Konstantin pada abad pertengahan dimana kekristenan menjadi identik dengan negara dan melegitimasi struktur negara sebagai sesuatu yang baik.

Tetapi hal tersebut kerap dilakukan oleh gereja-gereja di Indonesia. Teologi publik yang berbasiskan nasionalisme mengakibatkan gereja jatuh kepada dukungan yang tanpa sikap hati-hati kepada pemerintah yang dapat berakibat kepada dukungan status quo dalam arti mendukung semua kebijakan pemerintah atau negara. ${ }^{68}$ Mojau mengatakan kepercayaan yang berlebihan inilah yang menyebabkan gereja lupa akan bahaya-bahaya hegemoni di dalam rezim Orde Baru, seperti hegemoni pembangunan ekonomi yang kapitalistis, identitas kultural, dan politik. ${ }^{69}$

Sebagaimana yang dicita-citakan Hauerwas bahwa "the church first serve the world by helping the world to know what it means to be the world."70 Untuk mencapai hal ini gereja harus menjaga jarak dengan negara atau pemerintah dan menjadi model yang kontras dengan pemerintah.

\footnotetext{
68 Perwujudannya dapat dilihat dalam berbagai bentuk seperti munculnya Teologi Asas Tunggal yang menganalogikan pembangunan di Indonesia seperti bangsa Israel yang membangun di tanah perjanjian. Selain itu ada juga usaha pemberian nilai teologis terhadap UUD 1945 yang mengatakan orang Kristen setia pada konstitusi karena konstitusi bukan hanya berkaitan secara politis tapi juga dengan iman. Lih. Emmanuel Gerrit Singgih, Iman dan Politik dalam Era Reformasi di Indonesia (Jakarta: BPK Gunung Mulia, 2000), 15-16

69 Mojau, Meniadakan atau Merangkul, 140.

70 Hauerwas, A Community of Character, 50.
} 
Hubungan dekat antara gereja dan negara di masa lampau berdampak pada kebiasaan gereja untuk mendekatkan diri kepada pemerintah pada saat ini. ${ }^{71}$ Gereja perlu menjaga jarak dengan negara supaya gereja tidak terjebak dengan teologi publik yang berlandaskan ideologi yang akhirnya malah berujung pada dukungan tanpa sikap hati-hati terhadap negara. Dengan menjaga jarak dengan negara, gereja memiliki cara yang sehat untuk melihat dunia sebagai dunia. ${ }^{72}$

Sekalipun berada di dalam negara, gereja harus berani menyatakan perbedaannya dengan negara dan bersikap kritis dengan segala kebijakan dan ideologi negara sebagaimana yang dikatakan oleh Singgih:

Kita perlu belajar mengakhiri keterpesonaan kita pada negara dan kilauan kuasa pemerintah, dan menghubungkan diri kita dengan kuasa-kuasa yang ada secara proporsional...Negara dan bangsa ini mempunyai pemerintahan. Tetapi, kita tidak akan menganggap struktur-struktur ini sejajar dengan Allah. Kita hidup dengan Pancasila sebagai ideologi negara...[t]etapi Pancasila tidaklah sakti, dalam arti mempunyai kuasa transenden yang bekerja ex-opereoperato untuk menghasilkan perdamaian dan kesejahteraan bagi bangsa kita. Hanya Allah saja yang sakti. ${ }^{73}$

\section{Kekristenan sebagai Minoritas Kreatif}

Selain sebagai kritikan atas teologi publik yang berbasiskan nasionalisme, teologi publik Hauerwas juga dapat mendorong gereja berani menjadi minoritas kreatif. Keberadaan sebagai minoritas di dalam masyarakat mengakibatkan timbulnya perasaan minoritas kompleks pada orang Kristen sehingga menganggap perlunya menempel pada dan

71 Singgih, Iman dan Politik dalam Era Reformasi di Indonesia, 15.

72 Ibid., 23.

73 Ibid., 23. 
mendapatkan perlindungan dari pemerintah. Seringkali perasaan minoritas kompleks menjadikan orang Kristen bermental triumfalistik sehingga sikap sosial yang diperlihatkan kepada masyarakat menjadi eksklusif.

Orang Kristen tidak perlu menyangkal posisinya sebagai minoritas sebab dengan menerima fakta sebagai minoritas maka perasaan minoritas kompleks dapat diatasi. Sebagai minoritas, orang Kristen tidak perlu mencurigai semua orang Islam atau bersikap Islam phobia sehingga harus menyembunyikan diri di belakang tirai nasionalisme. ${ }^{74}$ Daripada tenggelam dalam minoritas kompleksnya, orang Kristen seharusnya menjadi minoritas kreatif. Orang Kristen dapat belajar dari orang Yahudi berjumlah sedikit di berbagai negara tetapi menunjukkan sumbangsihnya dimana mereka berada. Seorang rabi Yahudi, Jonathan Sacks, dalam Erasmus Lecture 2013, mengatakan:

[y]ou can be a minority, living in a country whose religion, culture, and legal system are not your own, and yet sustain your identity, live your faith, and contribute to the common good.... It isn't easy. It demands a complex finessing of identities. It involves a willingness to live in a state of cognitive dissonance. It isn't for the fainthearted. But it is creative. ${ }^{75}$

Pendapat Sacks ini juga berlaku bagi orang Kristen Indonesia. Sebagai minoritas kreatif, orang Kristen dapat tinggal di sebuah negara yang agama, budaya, dan sistem hukumnya berbeda dengan dirinya tetapi tetap memiliki identitas dan imannya dan dapat bersumbangsih bagi kebaikan bersama.

Dalam posisinya sebagai minoritas kreatif dalam masyarakat, gereja tidak perlu menghindari kemajemukan atau melarikan diri dari dialog.

\footnotetext{
74 Mojau, Meniadakan atau Merangkul, 322.

75 Jonathan Sacks, "On creative minorities" First Things no. 239 (January 1, 2014): 34-35.
} 
Hauerwas mengatakan tugas gereja bukanlah menyangkali "the reality of the multiplicity of stories in the world or to force the many stories into an artificial harmony" tetapi gereja bertugas untuk setia dengan "the story of God that makes intelligible the divided nature of the world."76 Orang Kristen harus mengakui banyaknya kepercayaan atau narasi di dalam dunia ini khususnya di Indonesia tetapi bukan malah melenyapkan keanekaragaman tersebut dalam harmoni buatan yang bernama nasionalisme.

Dalam dialog gereja harus setia dan berani menyatakan cerita yang dipegangnya di hadapan masyarakat yang majemuk. Hauerwas percaya komunitas Kristen dapat bekerjasama dengan komunitas yang lain walaupun bukan berdasarkan hukum alam tetapi karena kerajaan Allah lebih luas dan gereja harus mengakui kehadiran kerajaan Allah di tempattempat yang tidak diduga oleh gereja seperti pada orang-orang yang tidak percaya. ${ }^{77}$ Orang Kristen di Indonesia dapat bekerjasama dengan komunitas iman yang lain sekalipun tidak memiliki narasi yang sama karena kerajaan Allah lebih luas daripada gereja seperti yang dikatakan Hauerwas "the church does not posses Christ; his presence is not confined to the church. Rather, it is in the church that we learn to recognize Christ's presence outside the church."78

76 Hauerwas, A Community of Character, 91.

77 Hauerwas, "The Servant Community," 376-377.

78 Ibid., 372. 